\title{
Clinical Breast Examination
}

National Cancer Institute

\section{Source}

National Cancer Institute. Clinical Breast Examination. NCI Thesaurus. Code C70552.

An exam of the breast performed by a health care provider to check for lumps or other changes. 